\title{
Tanshinone I exerts cardiovascular protective effects in vivo and in vitro through inhibiting necroptosis via Akt/Nrf2 signaling pathway
}

Youqiong Zhuo ${ }^{1,2}$, Renyikun Yuan ${ }^{3}$, Xinxin Chen ${ }^{1,2}$, Jia He ${ }^{1,2}$, Yangling Chen ${ }^{1,2}$, Chenwei Zhang ${ }^{1,2}$, Kaili Sun $^{1,2}$, Shilin Yang ${ }^{1,2}$, Zhenjie Liu ${ }^{1,2}$ and Hongwei Gao ${ }^{1,2^{*}}$ (D)

\begin{abstract}
Background: Tanshinone I (TI) is a primary component of Salvia miltiorrhiza Bunge (Danshen), which confers a favorable role in a variety of pharmacological activities including cardiovascular protection. However, the exact mechanism of the cardiovascular protection activity of TI remains to be illustrated. In this study, the cardiovascular protective effect and its mechanism of TI were investigated.

Methods: In this study, tert-butyl hydroperoxide (t-BHP)-stimulated H9c2 cells model was employed to investigate the protective effect in vitro. The cell viability was determined by 3-(4, 5-dimethylthiazol-2-yl)-2, 5-diphenyl tetrazolium bromide (MTT) assay and lactate dehydrogenase (LDH) kit. The reactive-oxygen-species (ROS) level and mitochondrial membrane potential (MMP) were investigated by the flow cytometry and JC-1 assay, respectively. While in vivo experiment, the cardiovascular protective effect of TI was determined by using myocardial ischemia-reperfusion (MI/R) model including hematoxylin-eosin (H\&E) staining assay and determination of superoxide dismutase (SOD) and malondialdehyde (MDA). Tumor necrosis factor-a (TNF-a) and interleukin-6 (IL-6) release were detected by Enzyme-linked immunosorbent assay (ELISA). Receptor interacting protein kinase 1 (RIP1), receptor interacting protein kinase 3 (RIP3), receptor interacting protein kinase 3 (MLKL), protein kinase B (Akt), Nuclear factor erythroid 2 related factor 2 (Nrf2), Heme oxygenase-1 ( $\mathrm{HO}-1$ ) and NAD(P)H: quinone oxidoreductase-1 (NQO-1) were determined by western blotting.
\end{abstract}

Results: Our data demonstrated that TI pretreatment attenuated t-BHP and MI/R injury-induced necroptosis by inhibiting the expression of p-RIP1, p-RIP3, and p-MLKL. TI activated the Akt/Nrf2 pathway to promote the expression of antioxidant-related proteins such as phosphorylation of Akt, nuclear factor erythroid 2 related factor 2 (Nrf2), quinone oxidoreductase-1 (NQO-1) and heme oxygenase-1 (HO-1) expression in t-BHP-stimulated H9c2 cells. TI relieved oxidative stress by mitigating ROS generation and reversing MMP loss. In vivo experiment, TI made electrocardiograph (ECG) recovery better and lessened the degree of myocardial tissue damage. The counts of white blood cell (WBC), neutrophil (Neu), lymphocyte (Lym), and the release of TNF-a and IL-6 were reversed by TI treatment. SOD level was increased, while MDA level was decreased by TI treatment.

Conclusion: Collectively, our findings indicated that Tl exerted cardiovascular protective activities in vitro and in vivo through suppressing RIP1/RIP3/MLKL and activating Akt/Nrf2 signaling pathways, which could be developed into a cardiovascular protective agent.

\footnotetext{
*Correspondence: gaohongwei06@126.com

${ }^{1}$ College of Pharmacy, Guangxi University of Chinese Medicine, Nanning 530000, China
}

Full list of author information is available at the end of the article

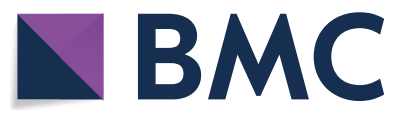

(c) The Author(s) 2021. This article is licensed under a Creative Commons Attribution 4.0 International License, which permits use, sharing, adaptation, distribution and reproduction in any medium or format, as long as you give appropriate credit to the original author(s) and the source, provide a link to the Creative Commons licence, and indicate if changes were made. The images or other third party material in this article are included in the article's Creative Commons licence, unless indicated otherwise in a credit line to the material. If material is not included in the article's Creative Commons licence and your intended use is not permitted by statutory regulation or exceeds the permitted use, you will need to obtain permission directly from the copyright holder. To view a copy of this licence, visit http://creativeco mmons.org/licenses/by/4.0/. The Creative Commons Public Domain Dedication waiver (http://creativecommons.org/publicdomain/ zero/1.0/) applies to the data made available in this article, unless otherwise stated in a credit line to the data. 
Keywords: Tanshinone I, Oxidative stress, Necroptosis, Myocardial ischemia reperfusion, RIP1/RIP3/MLKL, Akt/Nrf2

\section{Background}

The incidence and mortality of cardiovascular diseases have been increasing in recent years [1], and myocardial ischemia represents a major contributor to cardiovascular diseases [2]. Myocardial ischemia refers to the gradual decrease in blood perfusion to the heart, resulting in a reduction in oxygen supply to the heart and insufficient energy metabolism of the heart muscle, which cannot guarantee normal and regular work of the heart [3]. At present, the main therapeutic strategy is to restore the blood supply to the myocardial ischemia site in multiple ways. MI/R, one of the most representative models, will also bring about a series of metabolic disorders, dysfunction, and structural destruction of tissues and organs, such as arrhythmias, enlarged infarcted area, ventricular dysfunction, and energy metabolism disorders, and other additional reperfusion damage $[4,5]$. In addition, MI/R injury is a common and inevitable problem in coronary interventional therapy. In addition to intervention to solve the heart's large vessel problems, drug therapy has become the main method to improve this injury. Traditional Chinese medicine owns a variety of advantages and characteristics such as multi-component, multi-target, multi-path, and low economic cost [6, 7]. Therefore, it is of great significance to explore effective constituent to improve $M I / R$ injury.

$\mathrm{MI} / \mathrm{R}$ injury is the key to poor prognosis of patients [5]. The onset of this damage is related to calcium overload, inflammatory response, energy metabolism disorder and oxygen-free radicals. And it can cause damage to the myocardium [4], promote the occurrence of myocardial remodeling, increase myocardial infarction area and facilitate the release of various inflammatory factors $[8,9]$ and oxygen free radicals [10]. Among them, the production of oxygen free radicals is closely related to $\mathrm{MI} / \mathrm{R}$ injury. In patients with myocardial ischemia, the content of free radical scavenging agents will be reduced [11], leading to the rise of free radicals, which not only motivates cell damage but also accelerates cell death [12]. Accordingly, in the treatment of patients, effective scavenging of oxygen free radicals and cardiomyocytes' damage can be reduced by inhibition of the generation of oxygen free radicals.

Necroptosis, a form of necrosis, can be controlled, in which dead cells rupture and liberate components inside the cells incurring cell death. In contrast to apoptosis, necroptosis leads to fracture of the plasma membrane, thus cell contents overflow, bringing about inflammation and the triggering of the immune system. Necroptosis signals need the involvement of RIP1, RIP3, and MLKL kinase [13]. There is growing literature that programmed necrosis occupies a crucial part in MI/R [14]. Therefore, suppression of necroptosis is an alternative strategy for the treatment of cardiovascular diseases [15]. This study will start with RIP1/RIP3/MLKL signaling pathway to explore the relationship between programmed necrosis and $M I / R$, aiming to provide a new perspective of current research for the prevention and treatment of MI/R from the perspective of "programmed necrosis intervention" [16-18].

A previous study indicated that ROS always leads to cells necroptosis. Akt/Nrf2 pathway is crucial to modulate ROS generation [19]. Akt participates in the positive regulation of $\mathrm{Nrf} 2$ antioxidant. Then $\mathrm{Nrf} 2$ activated further separates from Keap1, entering into the nucleus to form dimers with Maf, recognizing and binding to the binding sites on ARE which will induce the transcription of NQO-1 as well as HO-1 to reduce oxidative stress injury $[19,20]$. Accordingly, the regulation of Akt/Nrf2 signaling pathway to reduce ROS generation-induced necroptosis will be an effective therapeutic strategy for the treatment of cardiovascular diseases.

Salvia miltiorrhiza Bunge (Danshen) is a traditional Chinese medicine that has widely incorporated into therapy for cardiovascular diseases through invigorating blood circulation and dispersing blood stasis [21]. Tanshinone I (TI) (Fig. 1a), a fat-soluble compound, is a major ingredience in Danshen [22]. However, the mechanism of cardiovascular protection of TI has not been revealed. Therefore, exploring the pharmacological effects of TI also provides new ideas for the treatment of cardiovascular diseases by Danshen. In this study, using t-BHP-stimulated $\mathrm{H} 9 \mathrm{c} 2$ cells and MI/R SD rat model, we investigated TI's cardiovascular protective effect and mechanism in vitro and in vivo.

\section{Materials and methods \\ Chemical and reagents}

Tanshinone I was purchased from Chengdu Pufei De Biotech Co., Ltd, (Chengdu, China), while its purity (over 98\%) was measured by HPLC. Verapamil hydrochloride was selected and bought from a Shanghai Macklin Biochemical Technology Co., Ltd, (Shanghai, China). 2', $7^{\prime}$-Dichlorodihydrofluorescein diacetate $\left(\mathrm{DCFH}_{2}-\mathrm{DA}\right)$, t-BHP, Dimethyl sulfoxide (DMSO), MTT and Necrostatin-1 (Nec-1) were obtained from Sigma-Aldrich (St. Louis, MO, USA). Double staining kit (7-AAD \& Annexin V-PE) was bought from BD Pharmingen ${ }^{\mathrm{TM}}$ 
a

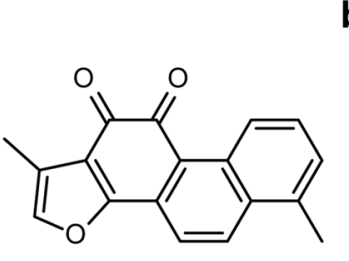

d
C

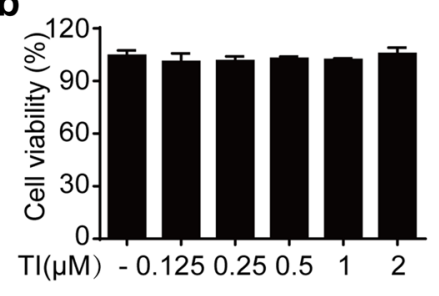

e

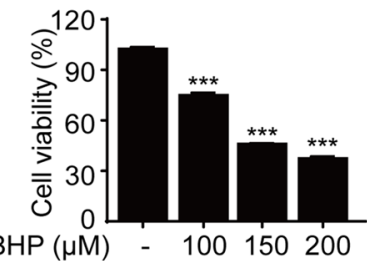

f

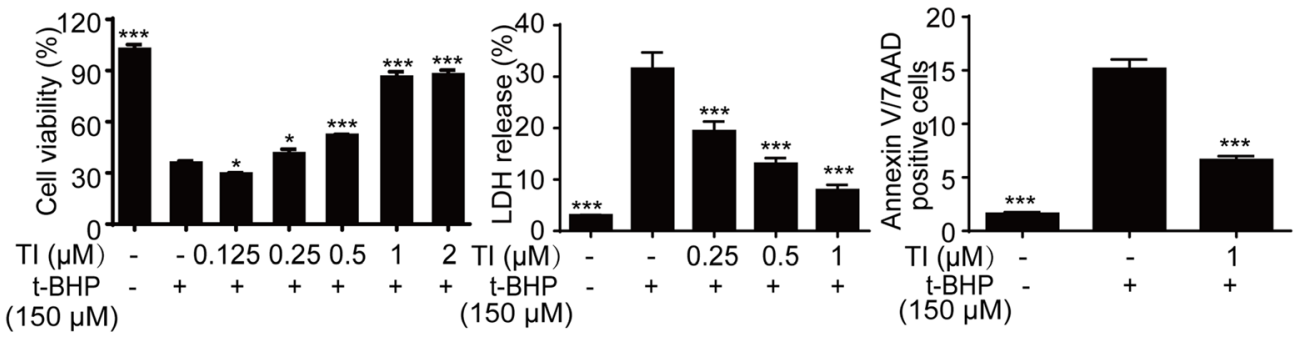

g
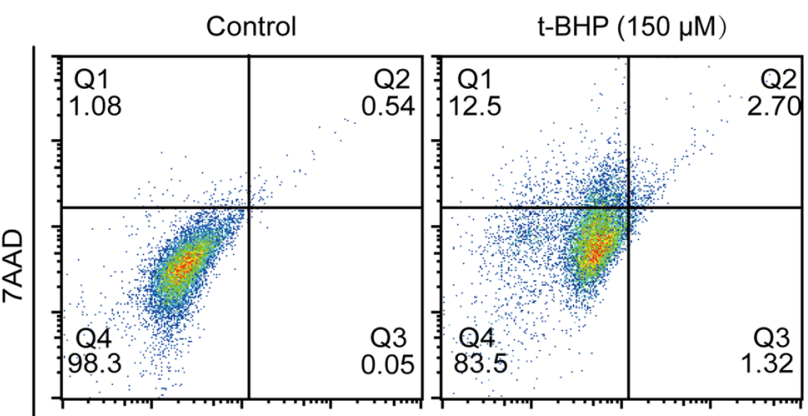

$\mathrm{t}-\mathrm{BHP}(150 \mu \mathrm{M})+\mathrm{TI}(1 \mu \mathrm{M})$

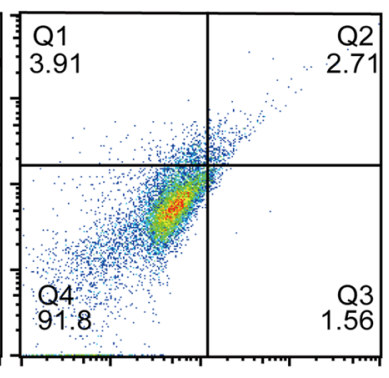

Annexin V

Fig. 1 Tanshinone I (TI) attenuated t-BHP-induced cell death in H9c2 cells. a The chemical structure of TI. b, c H9c2 cells were treated with TI or $\mathrm{t}-\mathrm{BHP}$ for a series of concentrations for $12 \mathrm{~h}$ or $10 \mathrm{~h}$ respectively, and cell viability was both tested by MTT. Cells were administrated with t-BHP for $10 \mathrm{~h}$ after treated with TI for $2 \mathrm{~h}$. $\mathbf{d}$ Employed MTT method to detect the viability of the cells. e Employed LDH kit to monitor the LDH level. $\mathbf{f}-\mathbf{g}$ Cells pretreated with TI (1 $\mu \mathrm{M})$ for $2 \mathrm{~h}$ before co-incubation with t-BHP $(150 \mu \mathrm{M})$ for $6 \mathrm{~h}$, were then stained with Annexin V-PE /7-AAD and detected by flow cytometry. $n=3$. $^{* *} p<0.001$ vs. t-BHP group

(Becton-Dickinson, NJ, USA). From Life Technologies/Gibco Laboratories (Grand Island, NY, USA), fetal bovine serum (FBS), as well as dulbecco's modified eagle medium (DMEM) were bought. JC-1 kit and LDH assay kit were obtained from Beyotime (Shanghai, China). From Thermo Fisher Scientific (Waltham, MA, USA), BCA protein detection kit was obtained. ELISA kits from Neobioscience (Shenzhen, China). MDA, as well as SOD detection kits, were purchased on selection from Nanjing Jiancheng Bioengineering Institute (Nanjing, China). Antibodies: p-RIP1 (AF7088), p-RIP3 (AF7443), p-MLKL (AF7420), RIP1(AF7877), and RIP3(AF7942) were purchased from Affinity Biosciences (Cincinnati, OH, USA), GAPDH (\#5174), p-Akt (\#4060), Akt (\#4691), HO-1 (\#70081), and secondary antibodies from Cell Signaling Technology (Beverly, MA, USA). MLKL (ab196436), Nrf2 (ab31163) and NQO1 (ab80588) were acquired from Abcam (Cambs, UK).

\section{Cell culture}

H9c2 cells, purchased from the Cell Bank of the Chinese Academy of Sciences (Shanghai, China), were placed in DMEM medium (10\% FBS and 1\% Penicillin/Streptomycin) for cultivation in an incubator containing $5 \% \mathrm{CO}_{2}$ with a specified temperature of $37^{\circ} \mathrm{C}$.

\section{Cell viability assay}

$4.0 \times 10^{3}$ cells per well were cultured in 96-well plates overnight, which were treated with TI $(0.125,0.25,0.5$, 1 , and $2 \mu \mathrm{M})$, Nec-1 $(20,40,80$, and $100 \mu \mathrm{M})$ or t-BHP (50, 100, and $150 \mu \mathrm{M}$ ) for $12 \mathrm{~h}, 12 \mathrm{~h}$ and $10 \mathrm{~h}$ subsequently. Our study employed MTT to detect the viability 
of cells and monitored the absorbance with a microplate reader (BioTek, Winkowski, VT, USA) at a wavelength of $570 \mathrm{~nm}$.

\section{Apoptosis assay}

H9c2 cells were cultured in 6-well plates $\left(1.5 \times 10^{5}\right.$ cells per well). Afterwards, $\mathrm{H} 9 \mathrm{c} 2$ cells were pretreated with TI $(1 \mu \mathrm{M})$ for $2 \mathrm{~h}$ and treated with t-BHP $(150 \mu \mathrm{M})$ for $6 \mathrm{~h}$. After collection, cells were stained with Annexin V-PE/7$\mathrm{AAD}$ and were detected by flow cytometry (BectonDickinson, NJ, USA).

\section{Measurement of lactate dehydrogenase (LDH) release} Inoculated on 96 -well plates $\left(4 \times 10^{3}\right.$ per well) overnight and pretreated with TI $(0.25,0.5$, and $1 \mu \mathrm{M})$ for $2 \mathrm{~h}$, H9c2 cells were co-cultured with t-BHP $(150 \mu \mathrm{M})$ for $10 \mathrm{~h}$. Medium was collected to measure LDH level as per the manufacturer's instruction of LDH. Using a microplate reader (490 $\mathrm{nm}$ wavelength), the absorbance was determined.

\section{Intracellular reactive oxygen species (ROS) detection}

H9c2 cells were seeded into 12 -well plates $\left(7.0 \times 10^{4}\right.$ cells per well) overnight and treated with t-BHP $(150 \mu \mathrm{M})$ for a different time, respectively, which subsequently were co-cultured with TI $(0.25,0.5$, and $1 \mu \mathrm{M})$ for $2 \mathrm{~h}$. Then cells were labeled with $\mathrm{DCFH}_{2}$-DA $(1 \mu \mathrm{M}, 0.5 \mathrm{~h})$, which were monitored by flow cytometry at the FITC channel. The images were captured by a fluorescence microscope (Leica, Wetzlar, Germany) [23].

\section{Mitochondrial membrane potential (MMP)'s detection assay}

Based on our anterior study [24, 25], cells were cultured in 96-well plates $\left(4.0 \times 10^{3}\right.$ cells in each well) overnight. After that, the cells were exposed to TI $(1 \mu \mathrm{M})$ for $2 \mathrm{~h}$ and cultured with t-BHP $(150 \mu \mathrm{M})$ up to $4 \mathrm{~h}$. For measuring the MMP, JC-1 $(5 \mu \mathrm{g} / \mathrm{mL})$ was co-cultured for $30 \mathrm{~min}$ and relevant images were captured by a fluorescence microscope.

\section{Animal experiments and ethical statement}

The study was authorized by the Experimental Animal Management Ethics Committee of Guangxi University of Traditional Chinese Medicine (Approval Document No. SYXK-GUI-2019-0001). As per the "Guidelines for the Care and Use of Laboratory Animals in Guangxi University of Traditional Chinese Medicine", all animals have received humane care. Healthy SD rats (male, 220-250 g) were purchased from Hunan Saike Jingda Experimental Animal Co. Ltd (Changsha, China) and acclimated for one week. Under normative SPF (specific pathogen-free) circumstances, all animals were housed and had free access to water as well as food with a befitting and controllable humidity $(50 \%)$ and temperature $\left(25^{\circ} \mathrm{C}\right)$.

Conventionally, the animals were divided into the sham-operated group, MI/R group, TI-L group (10 mg/ $\mathrm{kg})$, TI-H group $(20 \mathrm{mg} / \mathrm{kg})$, and positive drug Verapamil hydrochloride (Ver) group $(20 \mathrm{mg} / \mathrm{kg}$ ) at random and each group consisted of 15 rats. The rats were given preadministration for one week before modeling. The rats were intraperitoneally injected with TI once a day while the sham operation group and MI/R group were given the uniform amount of normal saline at the corresponding time.

\section{Construction of $\mathrm{MI} / \mathrm{R}$ SD rat model}

The MI/R rats were operated by transient myocardial ischemia for $0.5 \mathrm{~h}$ and reperfusion for $2 \mathrm{~h}$ therewith. In short, the experimental rats were narcotized by intraperitoneal injection of $10 \%$ chloral hydrate $(4 \mathrm{~mL} / \mathrm{kg})$. These rats were concatenated to a rodent ventilator (respiratory rate of $58-70$ breaths/min, respiratory ratio of $5: 4$, tidal volume of $6-7 \mathrm{~mL} /$ time). The third and fourth ribs were cut open, leaving the heart nearly entirely exposed. Then 6-0 silk suture was used to ligature LAD (the left anterior descending coronary artery) at the distal $1 / 3$. The heart grew grey promptly. The ligation was disentangled after occlusion for $30 \mathrm{~min}$, the heart going through reperfusion for $2 \mathrm{~h}$. The sham-operated group underwent the identical operation and was penetrated in absence of ligation. ECG changes were recorded throughout the whole experiment by BL-420N biological signal acquisition and analysis system (Chengdu, China).

\section{Histopathology examination}

Fixed with $4 \%$ paraformaldehyde and dehydrated with alcohol gradient, the heart tissue samples were then processed with xylene transparently and paraffin-embedded. Hematoxylin and eosin (H\&E) staining were employed after the samples were sectioned. Ultimately, with an optical microscope (UOP, DSZ5000X, China), the study observed the pathological changes of the tissue.

\section{Hematology analysis}

Blood was collected from the abdominal aorta of rats. WBC, Neu, and Lym count from blood were determined by an auto hematology analyzer (Mindray, Shenzhen, China).

\section{Determination of SOD, MDA, TNF- $a$, IL-6}

With a tissue grinder (Tianjin, China), SD rats' heart tissue was homogenized. The samples were centrifuged. Their supernatant was collected immediately and stored at $-80{ }^{\circ} \mathrm{C}$. As per the manufacturer's instructions, the 
SOD, MDA examined by corresponding kits, TNF- $\alpha$ and IL-6 levels were detected by ELISA kits.

\section{Western blotting analysis}

H9c2 cells were seeded into a dish overnight. TI $(0.25$, 0.5 , and $1 \mu \mathrm{M}$ ) was pretreated for $2 \mathrm{~h}$ and co-cultured with $\mathrm{t}$-BHP induction for $4 \mathrm{~h}$. The study employed RIPA (1\% PMSF and $1 \%$ cocktail) to extract total proteins of cells as well as the heart tissue. As per the manufacturer's instruction, the concentration of the protein was measured by the BCA protein kit [25]. Through $10 \%$ or $12 \%$ SDS-PAGE gels, the denatured protein was separated, which was transferred to polyvinylidene fluoride (PVDF) membrane (Millipore, Billerica, MA, USA). After $5 \%$ skim milk blocking the PVDF membrane up to $2 \mathrm{~h}$, incubate the membrane with 1:1000 primary antibodies (p-RIP1, p-RIP3, p-MLKL, RIP1, RIP3, MLKL, p-Akt, Akt, Nrf2, HO-1, NQO-1, GAPDH) at $4{ }^{\circ} \mathrm{C}$ for over $12 \mathrm{~h}$. The membrane was exposed to ChemiDoc ${ }^{\mathrm{TM}} \mathrm{MP}$ Imaging System (Bio-Rad, Hercules, CA, USA) after washing with TBST and incubating with secondary antibody (Antirabbit IgG, HRP-linked Antibody 1:5000) for $2 \mathrm{~h}$ at room temperature, of which GAPDH was the specified housekeeping protein.

\section{Statistical analysis}

Dates were presented as means \pm SD. All experiments were repeated at least three times. Dates were normally distributed and GraphPad Prism 6.0 software was used to perform one-way-ANOVA or Student's $t$-test. When $\mathrm{p}<0.05$, results were considered to be statistically significant.

\section{Results}

\section{Tl exerted protective effects on t-BHP-stimulated H9c2} cells

The cytotoxicity of TI was detected by the MTT method. The results indicated that TI $(0.125,0.25,0.5,1$, and $2 \mu \mathrm{M})$ displayed no significant toxicity in $\mathrm{H} 9 \mathrm{c} 2$ cells as exhibited in Fig. 1b. In contrast with the control group, t-BHP $(100,150$, and $200 \mu \mathrm{M})$ reduced cell viability to a diverse degree. $\mathrm{t}$-BHP $(150 \mu \mathrm{M})$ was selected as the befitting and conclusive concentration to conduct the following experiments (Fig. 1c). TI pretreatment could rescue t-BHP-stimulated cell death. (Fig. 1d). In addition, TI reversed t-BHP-induced LDH release in H9c2 cells (Fig. 1e). Simultaneously, apoptosis assay results indicated that TI significantly decreased t-BHP-induced cell death (Fig. 1f, g). All in all, these results indicated that TI exerted protective effects on t-BHP-stimulated H9c2 cells.

\section{TI ameliorated t-BHP-induced cell necroptosis via RIP1/ RIP3/MLKL pathway}

As shown in Fig. 2a, Nec-1 $(20-100 \mu \mathrm{M})$, the necroptosis inhibitor, had no cytotoxicity in H9c2 cells. Nec-1 could prominently inhibit t-BHP-stimulated H9c2 cells necroptosis, particularly the $100 \mu \mathrm{M}$ (Fig. 2b). Like the effect of Nec-1, TI significantly inhibited t-BHP-induced necroptosis (Fig. 2c), of which the effects were further confirmed by the LDH results (Fig. 2d). Microscopic images also comfimed this results (Additional file 1: Fig. S1). In addition, necroptosis was primarily mediated by the RIP1/RIP3/MLKL signaling pathway [26]. Compared with the control group, t-BHP augmented phosphorylation of RIP1, RIP3, and MLKL, of which TI could reverse these effects (Fig. 2e-h). Collectively, TI reversed t-BHPinduced necroptosis in $\mathrm{H} 9 \mathrm{c} 2$ cells.

\section{TI mitigated t-BHP-induced ROS generation in $\mathrm{H} 9 \mathrm{c} 2$ cells}

A sharp augment of ROS level can be stimulated by $\mathrm{t}-\mathrm{BHP}$, in the meantime, promoting oxidative stress [27]. The intracellular ROS generation was monitored by immunofluorescent assay and flow cytometry assay. As shown in Fig. 3a, b, t-BHP could augment the ROS level when H9c2 cells were irritated by t-BHP for $4 \mathrm{~h}$. As shown in Fig. 3c-d, TI observably suppressed t-BHPinduced ROS generation in $\mathrm{H} 9 \mathrm{c} 2$ cells. In addition, fluorescence microscopy was applied to the observation of ROS production. Results exhibited that TI $(1 \mu \mathrm{M})$ reduced $\mathrm{t}$-BHP-induced fluorescence intensity dramatically (Fig. 3e), which corresponded to the above results. To sum up, our results revealed that ROS level was lowered by TI, suggesting that TI owned the advantage of anti-oxidative activity.

\section{TI reversed t-BHP-induced mitochondrial-membrane-potential (MMP) loss}

t-BHP destroyed the stability of MMP, which was to the disadvantage of keeping normal physiological functions of cells [28]. The changes in MMP were observed by a fluorescence microscope. Results exhibited that under normal circumstances, JC-1 existed in the form of polymer in the cell mitochondria with vivid red fluorescence, and the MMP reduced after cells were treated with $\mathrm{t}-\mathrm{BHP}$, which JC-1 could not be present in the mitochondrial matrix as a polymer [29]. Under this circumstance, the red fluorescence's intensity was markedly decreased, while in the cytoplasm the green fluorescence was signally stronger. This situation was reversed dramatically when the cells were pretreated with TI $(1 \mu \mathrm{M})$. Collectively, TI $(1 \mu \mathrm{M})$ rescued t-BHP-stimulated MMP loss (Fig. 4a). 

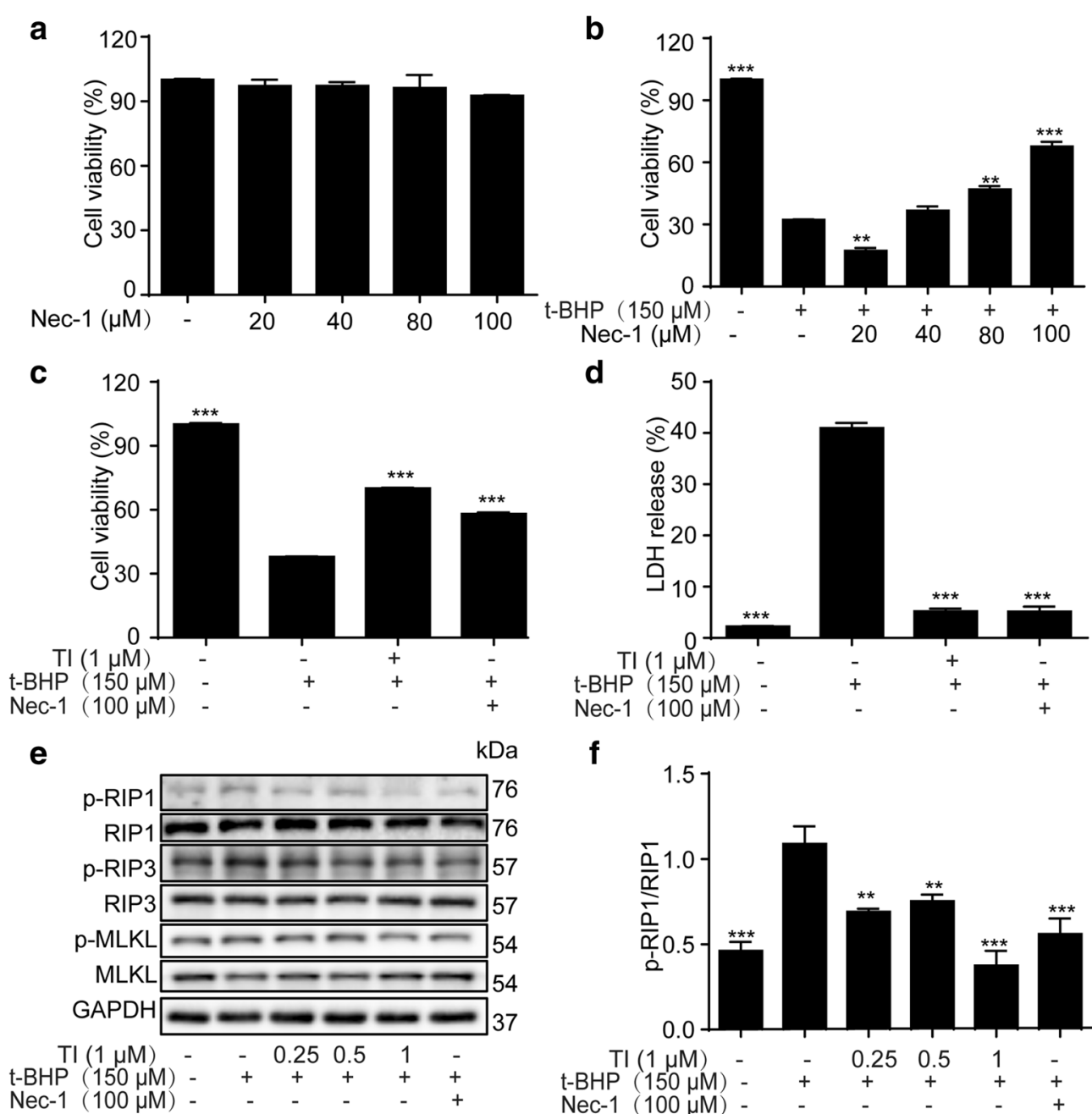

f
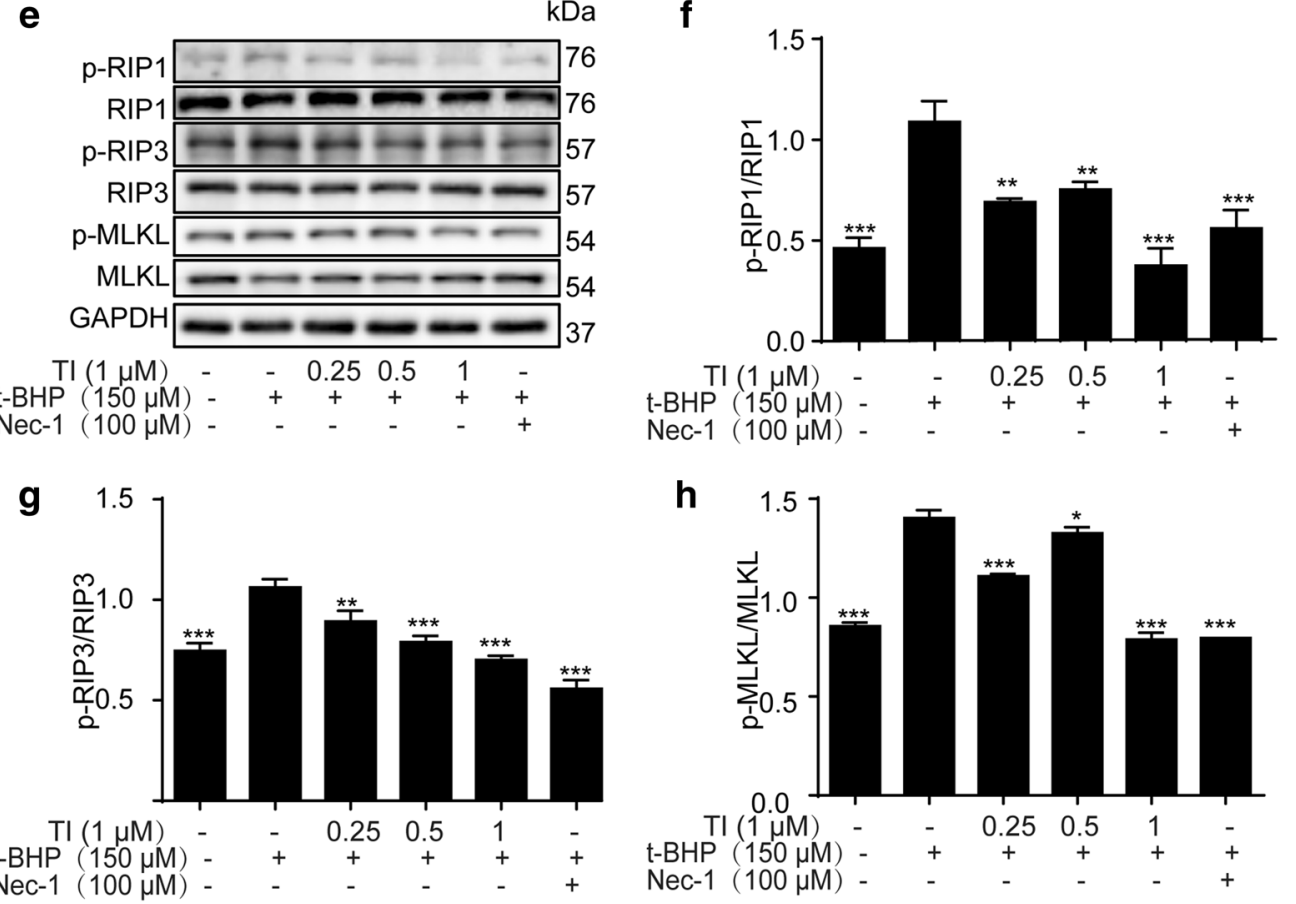

Fig. $2 \mathrm{Tl}$ ameliorated t-BHP induced cell necroptosis via RIP1/RIP3/MLKL pathway. a H9c2 cells were cultured with Nec-1 for $12 \mathrm{~h}$. b Cells were exposed to t-BHP $(150 \mu \mathrm{M})$ for $10 \mathrm{~h}$ after treated with Nec-1 for $2 \mathrm{~h}$. c Cells were exposed to t-BHP $(150 \mu \mathrm{M})$ for $10 \mathrm{~h}$ after treated with TI (1 $\mu \mathrm{M})$ or Nec-1 $(100 \mu \mathrm{M})$ for $2 \mathrm{~h}$. MTT was employed to detect cell viability. d Cells were treated with t-BHP $(150 \mu \mathrm{M})$ for $10 \mathrm{~h}$ when pretreated with TI $(1 \mu \mathrm{M})$ or Nec-1 $(100 \mu \mathrm{M})$ for $2 \mathrm{~h}$, the LDH level was monitored by LDH kit. e-h Pretreated with TI (0.25, 0.5, and $1 \mu \mathrm{M})$ or Nec- $1(100 \mu \mathrm{M})$ for $2 \mathrm{~h}$ respectively, then exposed to t-BHP $(150 \mu \mathrm{M})$ for $4 \mathrm{~h}$, the protein expression was determined by western blotting. $n=3 .{ }^{*} p<0.05,{ }^{* * *} p<0.01,{ }^{* * *} p<0.001$ vs. t-BHP group 


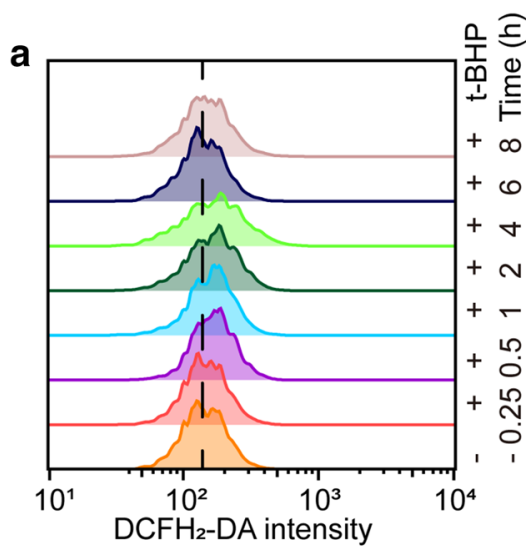

C
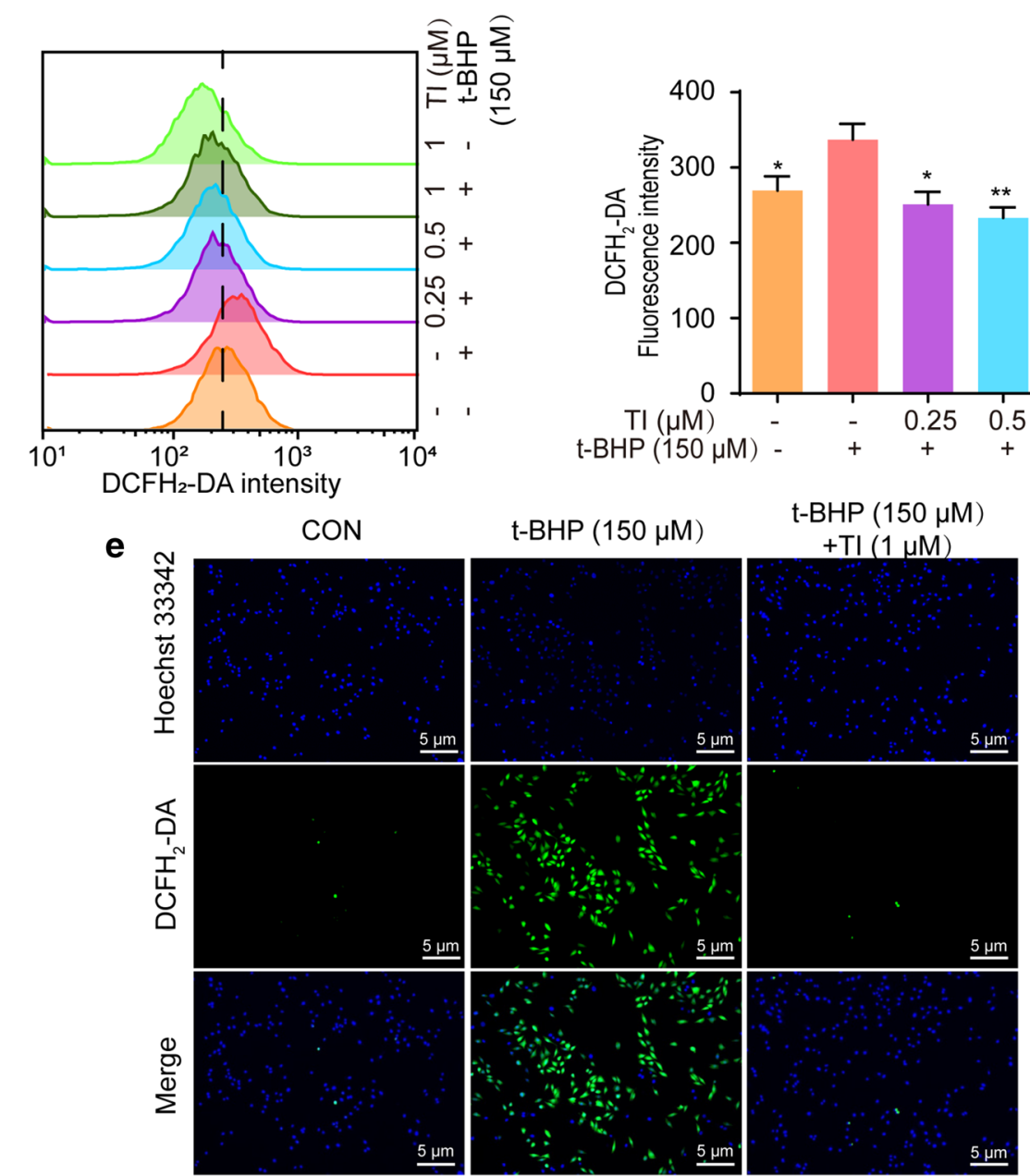

Fig. $3 \mathrm{Tl}$ mitigated ROS generation in $\mathrm{H} 9 \mathrm{c} 2$ cells. a H9c2 cells were exposed to t-BHP $(150 \mu \mathrm{M})$ at different points in time $(0,0.25,0.5,1,2,4,6$, and $8 \mathrm{~h})$ respectively. Cells labeled with DCFH 2 -DA $(1 \mu \mathrm{M})$ for $0.5 \mathrm{~h}$ were evaluated by flow cytometry. c Cells pretreated with $\mathrm{TI}(1 \mu \mathrm{M})$ for $2 \mathrm{~h}$, stimulated with t-BHP $(150 \mu \mathrm{M})$ for $4 \mathrm{~h}$, then, DCFH - -DA (1 $\mu \mathrm{M})$ was used to stain cells for $0.5 \mathrm{~h}$. The fluorescence intensity was detected by flow cytometry. $\mathbf{b}$, d Statistical analysis of the ROS per group. e Cells were stained with DCFH ${ }_{2}$-DA for the measurement of ROS level. The images were captured by fluorescence microscopy. $n=3 .{ }^{*} p<0.05,{ }^{* *} p<0.01,{ }^{* * *} p<0.00$ vs. t-BHP group. Scale bar: $5 \mu m$ 


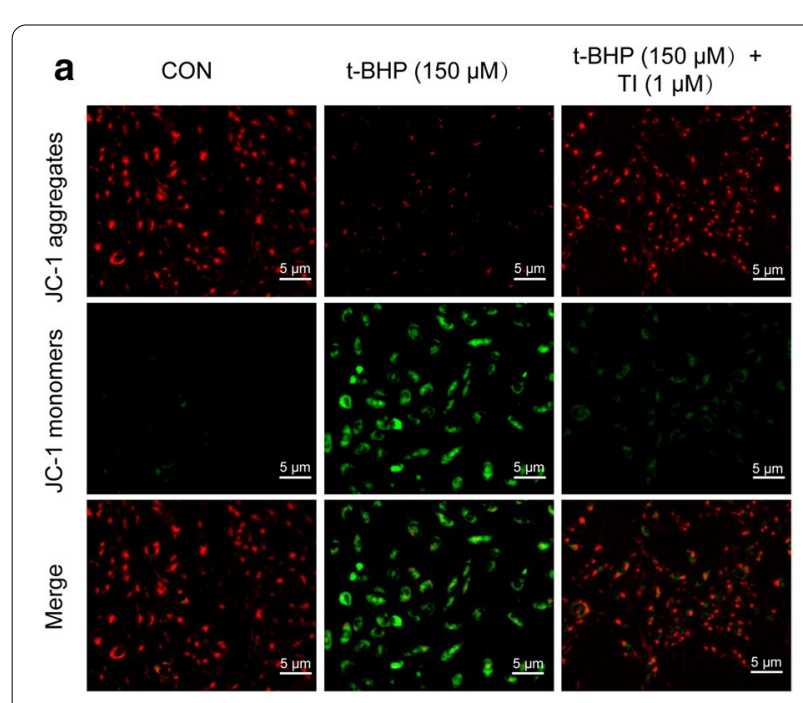

Fig. $4 \mathrm{TI}$ could reverse t-BHP-induced MMP loss. a Pretreated with $\mathrm{TI}(1 \mu \mathrm{M})$ for $2 \mathrm{~h}$, then exposed to t-BHP $(150 \mu \mathrm{M})$ for $4 \mathrm{~h}$, cells were then stained with $\mathrm{JC}-1(5 \mu \mathrm{g} / \mathrm{mL})$ for $0.5 \mathrm{~h}$ and under a fluorescence microscope, images were captured. Scale bar: $5 \mu \mathrm{m}$

\section{Tl activated Akt/Nrf2 signaling pathway to relieve oxidative stress injury}

Activation of Akt/Nrf2 signaling pathway occupies a crucial part in the process of anti-oxidative stress [30]. As depicted in Fig. 5a, b, t-BHP lead to the higher expression levels of p-Akt, while TI promoted this effect obviously without altering the Akt. Nrf2, one of the significant nuclear transcription factors, regulates constitutive and inducible expression of anti-oxidant and phase 2 detoxification enzymes coordinately, such as NQO-1 and HO-1 $[30,31]$. In the present study, TI markedly increased Nrf2, HO-1, and NQO-1 protein expression. (Fig. 5c-f). In summary, our results demonstrated that TI improved the expression of anti-oxidative-enzyme-related proteins after $\mathrm{t}$-BHP challenge to relieve oxidative stress injury.

\section{TI pretreatment improved cardiac function and alleviated MI/R injury in SD rats}

Cardiac function of rats after MI/R injury was detected by ECG. As indicated in Fig. 6a, under normal conditions, TI-treated rats showed no significant difference compared to that of the sham group, suggesting that TI showed no cardiotoxicity. The ST segment of all rats was observably elevated after ischemia, but gradually lowering after reperfusion. Besides, compared with the MI/R group, TI-treatment group and Ver-treatment group's ECG recovered better after $2 \mathrm{~h}$ reperfusion. The H\&E staining results revealed that the degree of myocardial tissue damage during $M I / R$ in rats. The myocytes of the sham operation group were normal without bleeding or neutrophil infiltration. Myocardial injury was severe in the ischemic area after MI/R. Myocardial fibers dissolved and infiltrated inflammatory cells. After MI/R, neutrophils congregated in ischemic areas of the heart. TI and Ver treatment alleviated MI/R-induced myocardial injury (Fig. 6b). The level of SOD was reduced by MI/R, but when TI pre-treatment, this change was reversed (Fig. 6c). On the contrary, TI pre-treatment decreased MDA level aggrandized by $M I / R$ in myocardial tissue (Fig. 6d).

\section{TI restored MI/R-induced imbalance of blood parameters} and inhibited inflammatory cytokines release

The blood amount of WBC, Neu, and Lym was the main inflammatory markers detected in routine blood tests [32]. When SD rats encountered MI/R, it caused inflammation. Contrasted with the sham group, the blood counts of WBC (Fig. 7a), Neu (Fig. 7b), and Lym (Fig. 7c) were substantially increased in the MI/R group. However, TI suppressed the abnormal rise of WBC, Neu, as well as Lym, of which its effects amounted to that of the positive drug, Verapamil. Besides, we detected the production of inflammatory cytokines of heart tissue. Compared with the sham operation group, the cytokines like TNF- $\alpha$ and IL- 6 levels were augmented after MI/R. In contrast, TI $(20 \mathrm{mg} / \mathrm{kg}$ ) could down-regulate IL-6 and TNF- $\alpha$ levels (Fig. 7d-e).

\section{TI pretreatment lightened myocardial necroptosis to ameliorate $\mathrm{MI} / \mathrm{R}$ injury}

The previous study indicated that MI/R injury always led to necroptosis in heart tissues [15]. In our study, using the heart tissues, we found that TI ameliorated MI/Rinduced necroptosis. As shown in Fig. 8, TI reversed MI/R-induced the phosphorylation of RIP1, RIP3, and MLKL protein expression.

\section{Discussion}

Cardiovascular disease with high morbidity and mortality is a severe threat to human health [33]. There is increasing evidence that Danshen's components can prevent cardiovascular diseases, especially atherosclerosis and heart diseases, including myocardial infarction, MI/R injury, arrhythmias, cardiac hypertrophy, and myocardial fibrosis. TI, one of the main fat-soluble components of Danshen, has been used to treat cardiovascular and inflammatory diseases. TI has a protective effect on ischemic injury and can inhibit the proliferation of vascular smooth muscle cells [22, 34]. It also has significant anti-inflammatory activity against both carrageenaninduced foot swelling and adjuvant-induced arthritis [35-38]. In this study, we chiefly focused on the cardiovascular protective effects of TI in vitro and in vivo. 

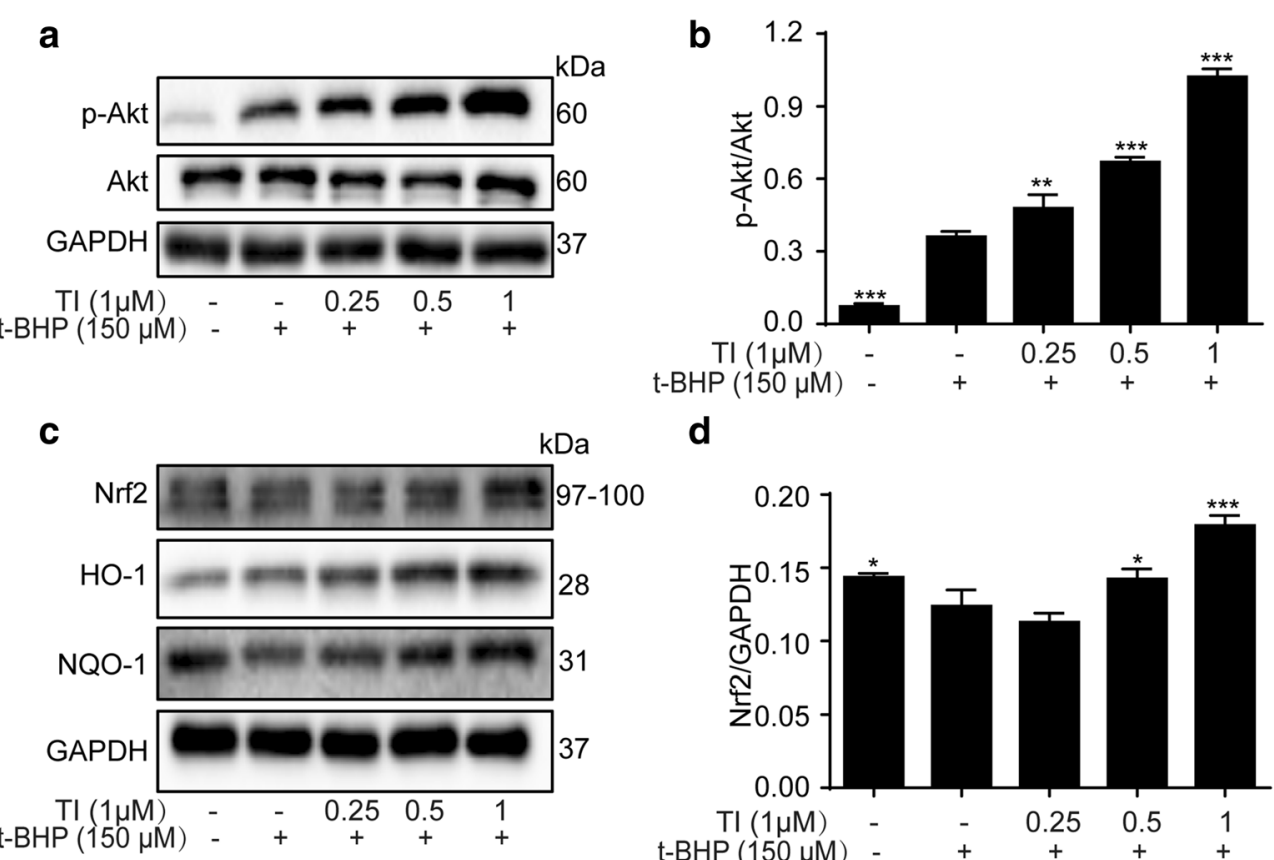

d
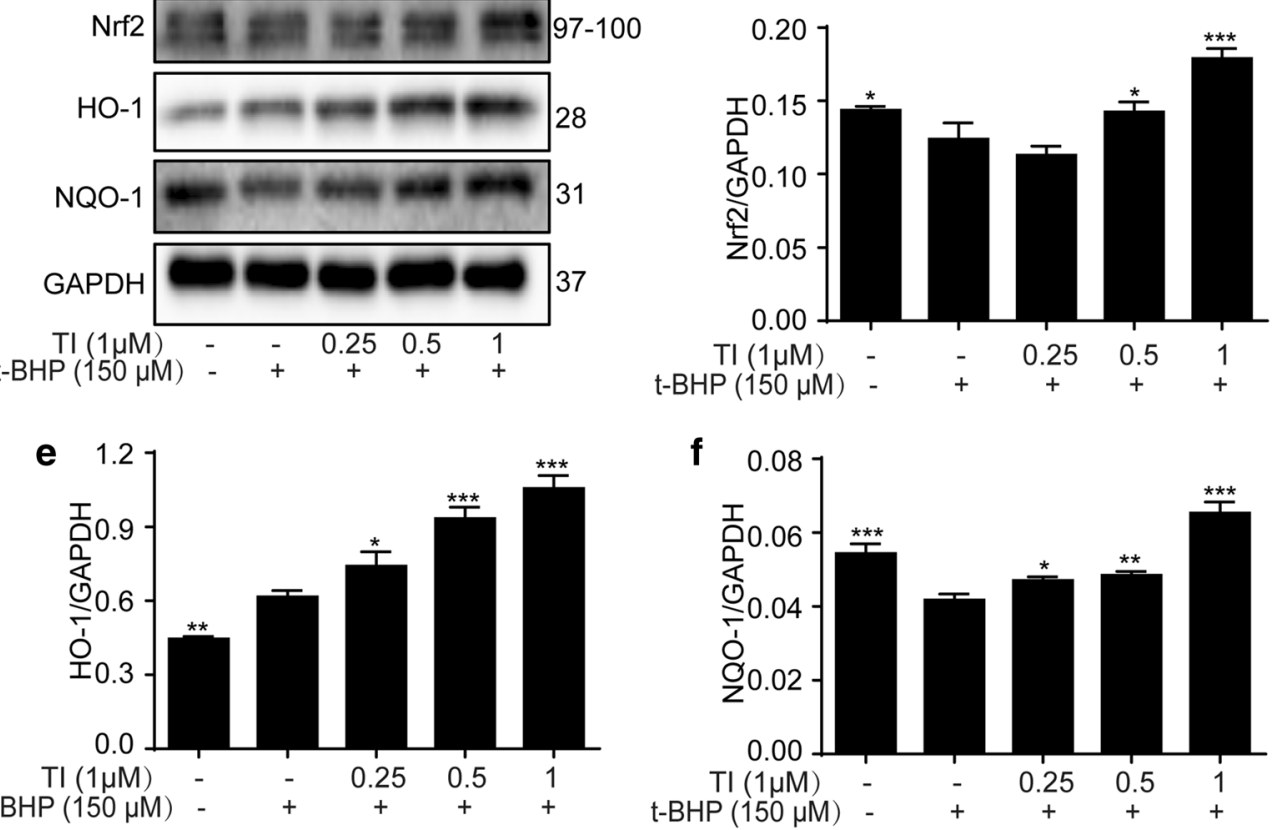

Fig. 5 The effect of Tl on Akt/Nrf2 pathway. a, $\mathbf{c ~ H 9 c 2}$ cells were pretreated with $\mathrm{Tl}(0.25,0.5$, and $1 \mu \mathrm{M})$ for $2 \mathrm{~h}$, and exposed to t-BHP (150 $\mu \mathrm{M})$ for $4 \mathrm{~h}$, therewith, the protein expression were detected by western blotting. Statistical analysis of protein expressions of $\mathbf{b} \mathrm{p}-\mathrm{Akt} / \mathrm{Akt}, \mathbf{d ~ N r f 2 ,} \mathbf{e ~ H O}-1, \mathbf{f}$ NQO-1. $n=3 .{ }^{*} p<0.05,{ }^{* *} p<0.01,{ }^{* * *} p<0.00$ vs. t-BHP group

The imbalance of cell death promotes the pathogenesis of cardiovascular diseases and is a clinical target therapy in the course of disease occurrence [14, 39]. Necrosis, previously considered as an unregulated form of cell death, has been recognized as a highly regulated process up to now and has attracted widespread attention in the past decade $[39,40]$. In addition, necroptosis, a kind of programmed necrosis, would be exacerbated in t-BHPinduced endothelial cells [28]. Recent evidence showed that a significant increase in intracellular ROS results in cell necroptosis [41, 42]. ROS is involved in TNF-induced necroptosis of human colon adenocarcinoma HT-29 cells [41]. t-BHP, a better alternative for unstable $\mathrm{H}_{2} \mathrm{O}_{2}$, is an organic peroxide broadly used in multiple oxidative stress studies and can liberate ROS, resulting in oxidative stress injury [43]. Whereas still much less is known about the contribution of t-BHP-stimulated oxidative stress injury and necroptosis in H9c2 cells. Furthermore, it has been reported that enhanced Akt phosphorylation promotes cardiac myocyte survival $[19,44]$. And Nrf2 is normally deemed to be a key transcription factor in anti-oxidative stress by strengthening antioxidant genes' expression such as HO-1 and NQO-1. In this study, we found that TI could conspicuously decrease ROS generation (Fig. 3a-e) and relieve oxidative stress injury through activating Akt/Nrf2 signaling pathways, promoting the phosphorylation of Akt, and the expression of anti-oxidative-enzyme-related proteins, namely Nrf2, NQO-1 and HO-1(Fig. 5a-f). Even superfluous ROS impacted mitochondria performance by decreasing MMP negatively [45], which was mitigated by TI $(1 \mu \mathrm{M})$ (Fig. 4a). 


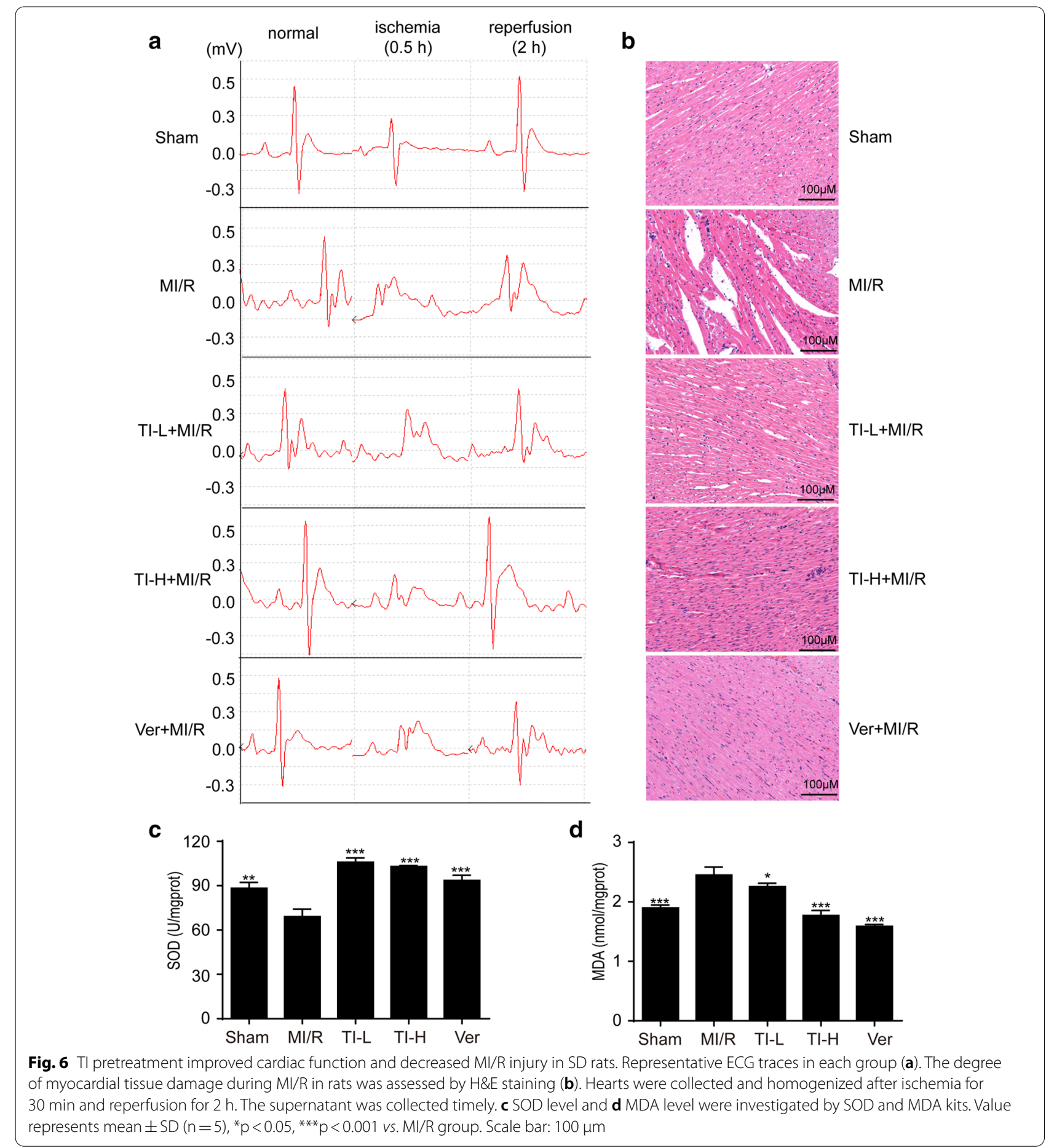

$\mathrm{MI} / \mathrm{R}$ injury is an urgent problem in clinical treatment [46]. MI/R injury irreversibly damage the structure and function of the heart [4]. With the in-depth study on the anti-MI/R injury efficacy of traditional Chinese medicine, it has been confirmed that it can alleviate MI/R injury by regulating programmed necrosis [47]. TNFR1-induced necroptosis is incurred by a signaling cascade referring to special serine-threonine proteins RIP1, RIP3, and MLKL [48]. Nevertheless, potential therapeutic reagents, such as Nec-1 inhibitor, could offer protection from the adverse 


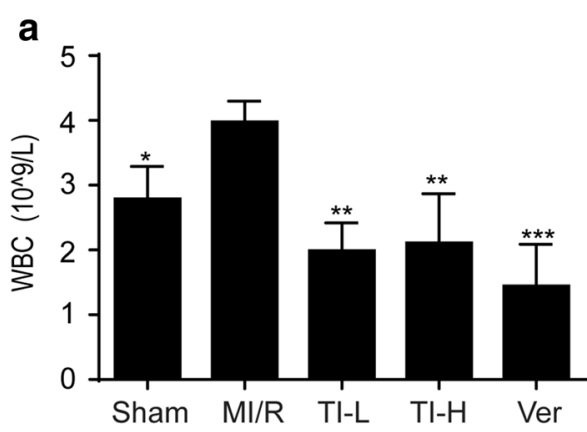

C

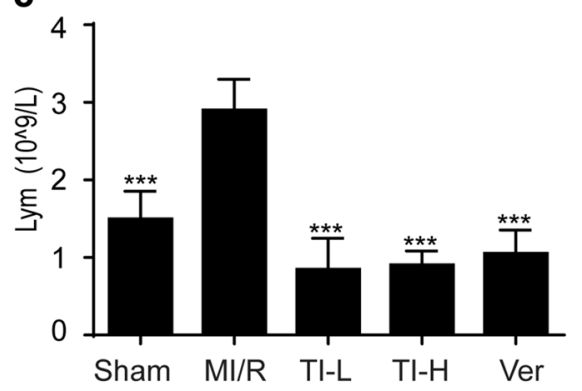

d

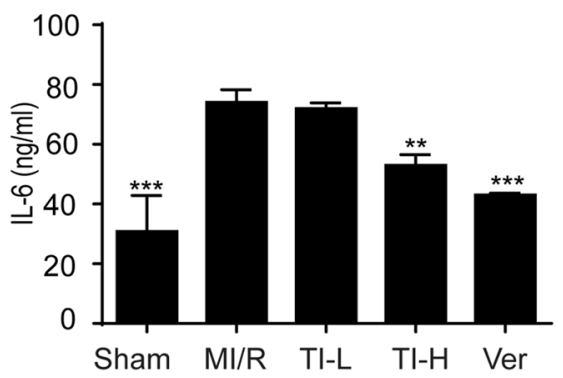

b

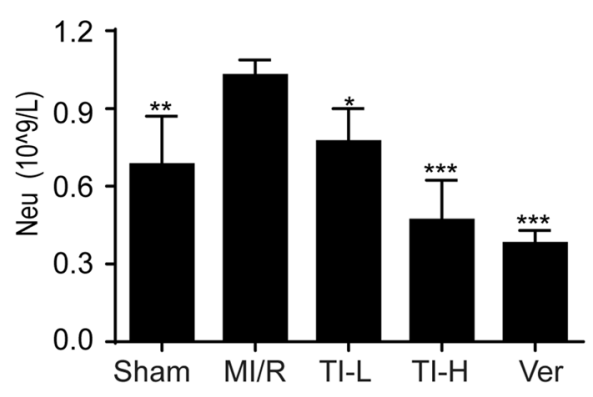

d

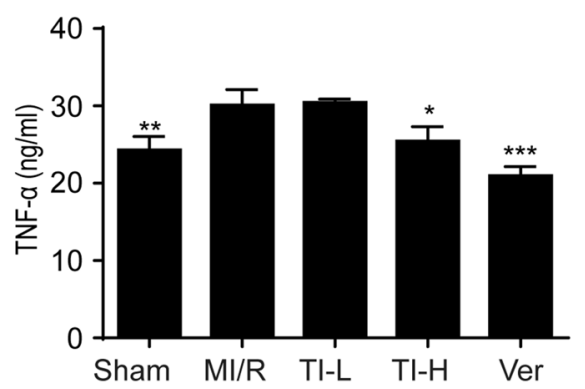

Fig. $7 \mathrm{TI}$ pretreatment decreased MI/R injury and inhibited the appearance of inflammation. After $30 \mathrm{~min}$ of ischemia and $2 \mathrm{~h}$ of reperfusion, blood was collected from the abdominal aorta of rats. a Count the amount of WBC. $\mathbf{b}$ The number of Neu was counted. $\mathbf{c}$ The counts of lymphocyte (Lym). Hearts were collected, homogenized. The samples were centrifuged $\left(4^{\circ} \mathrm{C}\right)$, the supernatant was collected timely. $\mathbf{d}$ TNF- $\mathrm{a}$, and $\mathbf{e} \mathrm{IL}-6 \mathrm{levels}$ were investigated by ELISA kits following the manufacturer's instructions. Value represents mean $\pm S D(n=5),{ }^{*} p<0.05,{ }^{* *} p<0.01,{ }^{* * *} p<0.001 \mathrm{vs}$. MI/R group

effects of necroptosis [49]. Hence, our study focused on the relation between MI/R and necroptosis. Gratifyingly, TI conferred a favorable role in the improvement of MI/R injury via restraining $\mathrm{p}-\mathrm{RIP} 1, \mathrm{p}-\mathrm{RIP3}$, and $\mathrm{p}-\mathrm{MLKL}$ expression (Fig. 8a-d).

Under physiological conditions, ROS acts as a second messenger to regulate a variety of signaling pathways [50]. Nonetheless, excess intracellular ROS leads to damage to the molecular components of cells, contributing to a wide variety of pathogenesis human diseases. A large number of studies have shown that ROS production is closely related to the process of cell death and promotes the occurrence of cell death as well as the development of cardiovascular diseases. Studies have shown that when myocardial ischemia, blood recovers after hypoxia, and oxygen supply will produce overmuch ROS, which will culminate in oxidative stress in the myocardium induced $\mathrm{MI} / \mathrm{R}$ injury [51]. Electron paramagnetic resonance (EPR) was employed to directly measure myocardial free radicals and it was found that a large amount of ROS was produced immediately after MI/R, which lasted for tens of minutes [52]. Fortunately, SOD is the main antioxidant enzyme that removes oxidative free radicals in the body, and its activity can reflect the ability to reduce oxidative free radicals. When ROS reacts with a polyunsaturated fatty acid, its lipid peroxide products, such as MDA, can 

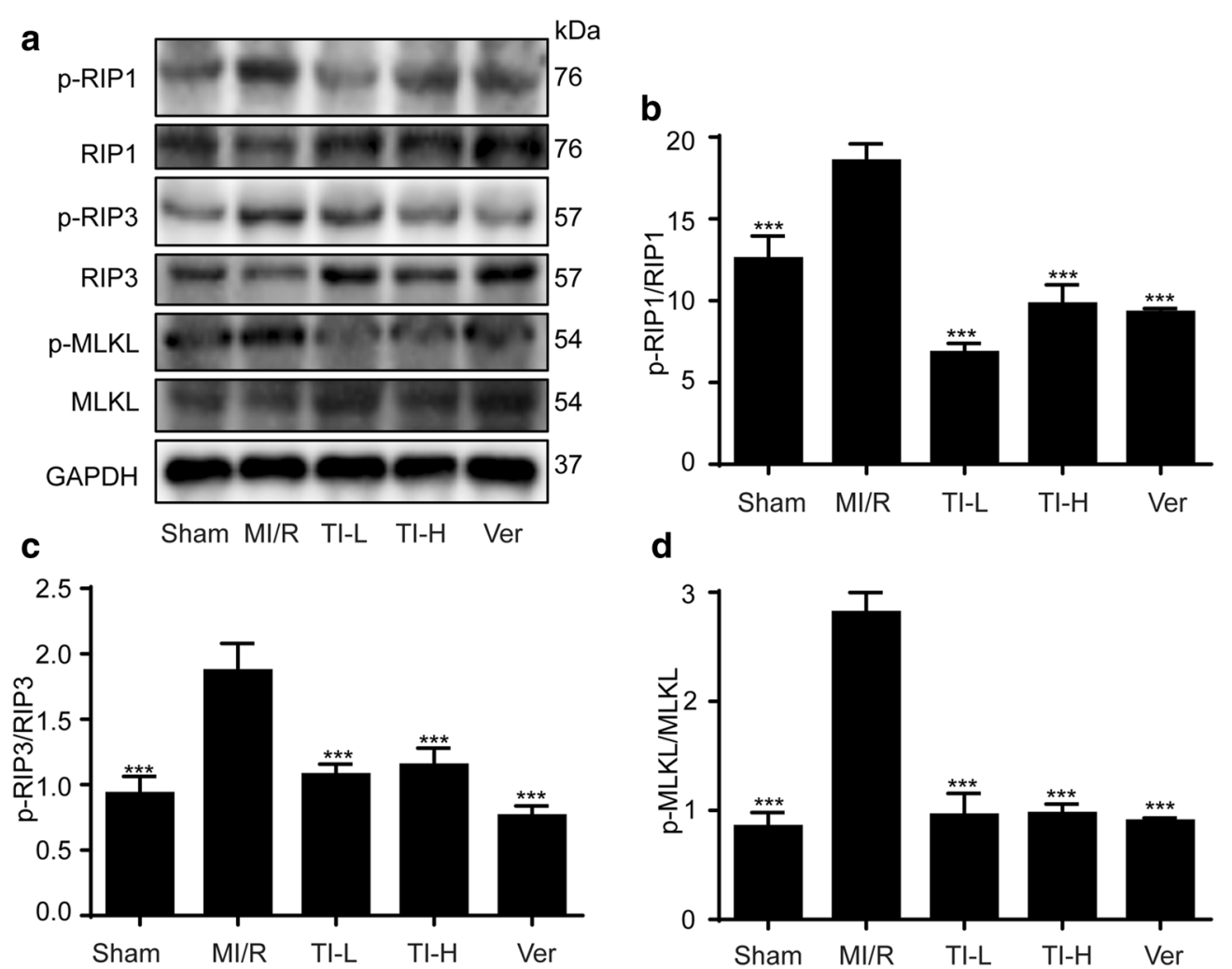

Fig. 8 TI pretreatment lightened myocardial necroptosis to improve MI/R injury by RIP1/RIP3/MLKL pathway. After ischemia for 30 min and reperfusion for $2 \mathrm{~h}$, hearts were collected, homogenized. The supernatant was collected to detect the related necroptosis proteins (a). The protein expressions of $\mathbf{a}, \mathbf{b}$ p-RIP1/RIP1, a, c p-RIP3/RIP3, a, $\mathbf{d}$ p-MLKL/MLKL were evaluated by western blotting. Value represents mean $\pm S D(n=5)$, ${ }^{* *} p<0.01,{ }^{* * *} p<0.001$ vs. MI/R group

reflect its lipid peroxide damage and indirectly indicate the injury of ROS to the body [53, 54]. Our research elucidated that the level of SOD was reduced by MI/R in contrast with sham operation group and this effect was reversed by TI pre-treatment (Fig. 6c). Oppositely, the level of MDA in heart tissue was aggrandized by MI/R and TI pre-treatment observably decrease this effect (Fig. 6d). which manifested the anti-oxidative properties of TI.

Of note, not only does the generation of ROS mediate the above aspects, but also it promotes inflammatory response [55]. Inflammatory response is the main cause of further myocardial damage and dysfunction. More and more evidences show that a large number of inflammatory mediators and chemokines are produced in the process of MI/R injury. Activated neutrophils can secrete cytokines, such as TNF- $\alpha$ and IL- 6 , which can further damage the myocardium, leading to metabolic dysfunction, degeneration and necrosis, etc. [56-59]. TNF- $\alpha$ is a crucial pro-inflammatory cytokine, which exerts key effects in the synthesis and release of inflammatory mediators, complement activation, and other physiological responses [38]. A pivotal cytokine, IL-6, is produced by fibroblasts as well as $\mathrm{T}$ cells, which are in a state of activation, and occupy comprehensive biological activities, for instance, immune regulation [60, 61]. Accumulating evidence has indicated that not only can IL-6 catalyze inflammatory response, but also it can amplify it. Its level of expression is able to reflect the seriousness of tissue cell injury effectually, and IL- 6 can be utilized as a valid index for chronic as well as acute inflammation in terms of clinical diagnosis [62]. Our study showed that TI could prevent myocardial fibers dissolved and infiltrated inflammatory cells (Fig. 6b). TI lowered the amount of WBC, Neu and Lym in blood of rats encountering MI/R (Fig. 7a-c). Besides, TI exerted significant inhibitory effects on TNF- $\alpha$ and IL-6 (Fig. 7d, e). Therefore, TI owned a prominently protective effect on assuaging $\mathrm{MI} / \mathrm{R}$ injury.

\section{Conclusion}

To sum up, our data indicated that TI could relieve t-BHP-stimulated oxidative stress injury by suppressing RIP1/RIP3/MLKL and activating Akt/Nrf2 signaling 


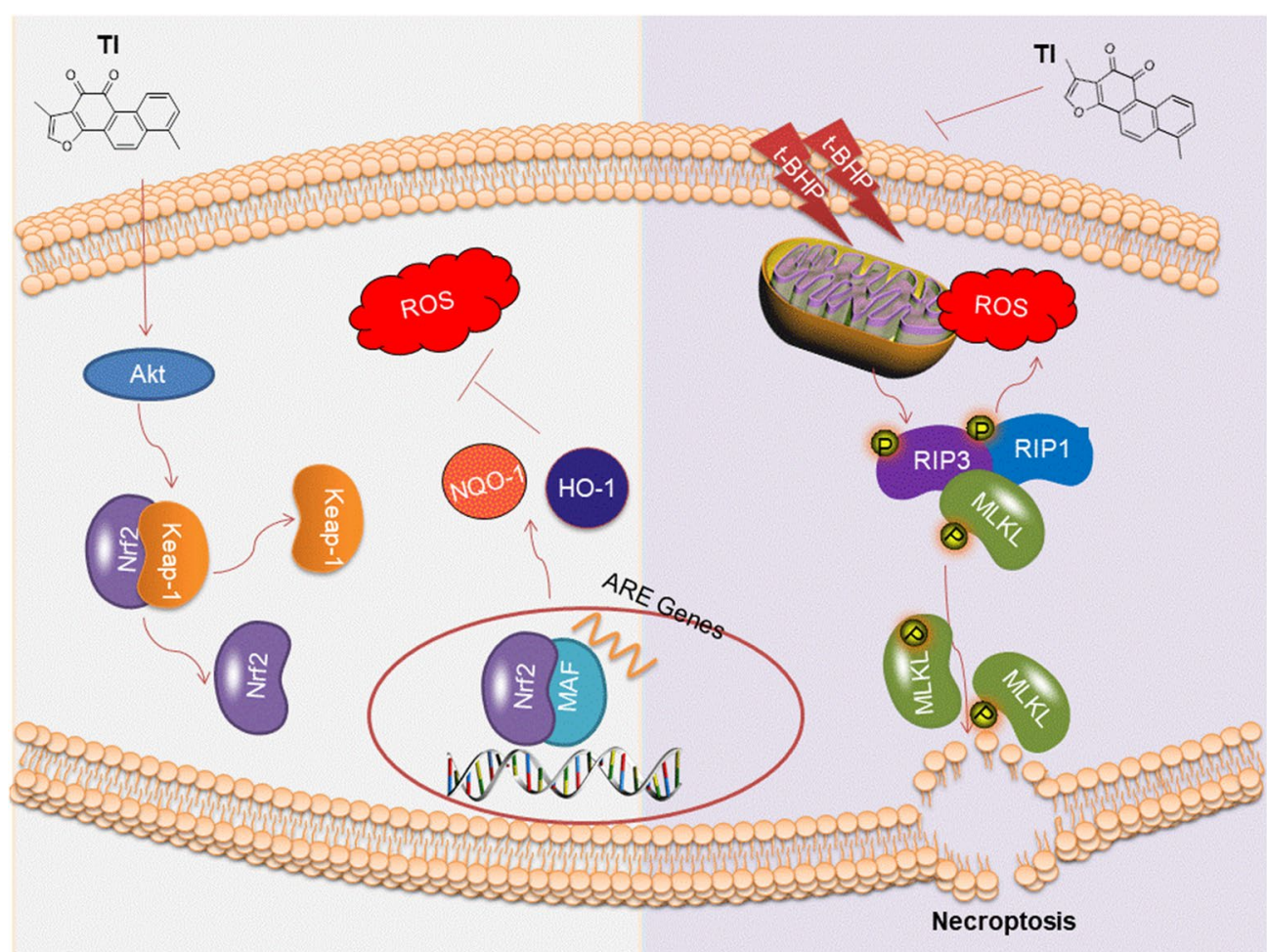

Fig. 9 The schematic of cardiovascular protective effects of TI in vitro. The mechanism of Tl's anti-oxidative effects and its effect on alleviating necroptosis in vitro was through Akt/Nrf2 and RIP1/RIP3/MLKL signaling pathways

pathways (As shown in Fig. 9). Also, TI could improve cardiac function in response to $\mathrm{MI} / \mathrm{R}$ injury by regulation of RIP1/RIP3/MLKL signaling pathway. These underlying mechanisms of TI highlighted that TI owned the advantage of promising cardiovascular protection activities, which facilitated the development of a novel agent for the treatment of cardiovascular diseases.

\section{Abbreviations}

TI: Tanshinone I; t-BHP: Tert-butylhydroperoxide; Ver: Verapamil hydrochloride; MTT: 3-(4,5-Dimethylthiazol-2-yl)-2,5-diphenyl tetrazolium bromide; LDH: Lactate dehydrogenase; ROS: Reactive-oxygen-species; MMP: Mitochondrial membrane potential; MI/R: Myocardial ischemia-reperfusion; H\&E: Hematoxylin-eosin; SOD: Superoxide dismutase; MDA: Malondialdehyde; TNF-a:Tumor necrosis factor-a; IL-6: Interleukin-6; RIP1: Receptor interacting protein kinase 1; RIP3: Receptor interacting protein kinase 3; MLKL: Mixed lineage kinase domain-like protein; WBC: White blood cell; Neu: Neutrophils; Lym: Lymphocyte; DMEM: Dulbecco's modified eagle medium; DMSO: Dimethylsulfoxide; ELISA: Enzyme-linked immunosorbent assay; FBS: Fetal bovine serum; Nrf2: Nuclear factor erythroid 2 related factor 2; HO-1: Heme oxygenase-1; NQO-1: $\mathrm{NAD}(\mathrm{P}) \mathrm{H}$ : quinone oxidoreductase-1; PVDF: Polyvinylidene fluoride; ECG: Electrocardiograph; EPR: Electron paramagnetic resonance; LAD: Left anterior descending coronary artery.

\section{Supplementary Information}

The online version contains supplementary material available at https://doi. org/10.1186/s13020-021-00458-7.
Additional file 1: Fig. S1 The detection of cells' morphological changes. H9c2 cells were pretreated with $\mathrm{TI}(1 \mu \mathrm{M})$ or nec-1 $(100 \mu \mathrm{M})$ for $2 \mathrm{~h}$, then exposed to t-BHP $(150 \mu \mathrm{M})$ for $6 h$, the cellular morphology was detected by microscope (Olympus, Tokyo, Japan).

\section{Acknowledgements}

We would like to appreciate the technological support from Qiongming Xu (Soochow University) and Liba Xu (Guangxi University of Chinese Medicine).

\section{Authors' contributions}

$H G, S Y$, and RY designed the research. $Y Z, X C$, and JH conducted the experiments. YZ and HG wrote the manuscript. RY, YC, CZ, KS and ZL revised the manuscript. All authors read and approved the final manuscript.

\section{Funding}

We would like to appreciate the support from Guangxi Science and Technology Base and Talent Special Project (2018AD19034), the Project of Guangxi Innovation-driven Development (2019AA17002), Guangxi Key Research and Development Plan (2020AB39014), the National Natural Science Foundation of China (NSFC, 81803807, 81860711, China), Guangxi Natural Science Foundation (2018JJB140265, 2018JJB140263), Qihuang High-level Talent Team Cultivation Project of Guangxi University of Chinese Medicine (2021002), and the Project of Guangxi Overseas "100 persons plan" High-level Expert. Guangxi Higher Education institutions Comprehensive Improvement Project 2021: Guangxi Collabrative Innovation Center for Scientific Achievements Transformation and Application on Traditional Chinese Medicine (0502101003).

\section{Availability of data and materials}

Not applicable. 


\section{Declarations}

\section{Ethics approval and consent to participate}

The study was established according to the ethical guidelines and approved by the Ethics Committee on Laboratory Animal Management of Guangxi University of Chinese Medicine.

\section{Consent for publication}

We declare that the Publisher has the Author's permission to publish the relevant contribution.

\section{Competing interests}

The authors declare no competing conflict of interests.

\section{Author details}

${ }^{1}$ College of Pharmacy, Guangxi University of Chinese Medicine, Nanning 530000, China. ${ }^{2}$ Guangxi Engineering Technology Research Center of Advantage Chinese Patent Drug and Ethnic Drug Development, Nanning 530200, China. ${ }^{3}$ State Key Laboratory of Innovative Drug and Efficient Energy-Saving Pharmaceutical Equipment, Jiangxi University of Traditional Chinese Medicine, Nanchang 330004, China.

Received: 27 March 2021 Accepted: 16 June 2021

Published online: 28 June 2021

\section{References}

1. Gam A, Gar B, Fuster CV. The global burden of cardiovascular diseases and riskfactors: 2020 and beyond-ScienceDirect. J Am Coll Cardiol. 2019;74(20):2529-32.

2. Fioranelli M, Bottaccioli AG, Bottaccioli F, Bianchi M, Rovesti M, Roccia MG. Stress and inflammation in coronary artery disease: a review psychoneuroendocrineimmunology-based. Front Immunol. 2018;9:1-15.

3. Pagliaro BR, Cannata F, Stefanini GG, Bolognese L. Myocardial ischemia and coronary disease in heart failure. Heart Fail Rev. 2019;25(1):53-65.

4. Heusch G. Myocardial ischaemia-reperfusion injury and cardioprotection in perspective. Nat Rev Cardiol. 2020;17(12):1-17.

5. Hausenloy DJ, Yellon DM. Ischaemic conditioning and reperfusion injury. Nat Rev Cardiol. 2016;13(4):193-209.

6. Han JY, Li Q, Pan CS, Sun K, Fan JY. Effects and mechanisms of QiShenYiQi Pills and major ingredients on myocardial microcirculatory disturbance, cardiac injury and fibrosis induced by ischemia-reperfusion. Pharmacol Res. 2019;147:1-49.

7. Mokhtari-Zaer A, Marefati N, Atkin SL, Alexandra A, Butler E. The protective role of curcumin in myocardial ischemia-reperfusion injury. J Cell Physiol. 2019;234(1):214-22.

8. Hu H, Zhai C, Qian G, Gu A, Liu J. Protective effects of tanshinone IIA on myocardial ischemia reperfusion injury by reducing oxidative stress, HMGB1 expression, and inflammatory reaction. Pharm Biol. 2015;53(12):1752-8.

9. Stefano T, Mauro AG, Cutter SZ, Antonio A. Inflammasome, pyroptosis, and cytokines in myocardial ischemia-reperfusion injury. AJP Heart Circul Physiol. 2018;315(6):1-63.

10. Schanze N, Bode C, Duerschmied D. Platelet contributions to myocardial ischemia/reperfusion injury. Front Immunol. 2019;10:1-9.

11. Ming-Shuo S, Hang J, Xin S, Shuo H, Fu-Liang Z, Zhen-Ni G, et al. Free radical damage in ischemia-reperfusion injury: an obstacle in acute ischemic stroke after revascularization therapy. Oxid Med Cell Longev. 2018:2018:1-17.

12. Cadenas S. ROS and redox signaling in myocardial ischemia-reperfusion injury and cardioprotection. Free Radical Biol Med. 2018;117:76-89.

13. Wang Z, Zhang $P$, Wang $Q$, Sheng $X$, Fan $X$. Protective effects of ginkgo biloba dropping pills against liver ischemia/reperfusion injury in mice. Chinese Med. 2020;15:1-12

14. Zhu H, Sun A. Programmed necrosis in heart disease: molecular mechanisms and clinical implications. J Mol Cell Cardiol. 2018;1 16:125-34.

15. Zhou W, Yuan J. Necroptosis in health and diseases. Semin Cell Dev Biol. 2014;35:14-23.
16. Sun $T$, Ding $W, X u T, A o X$, Wang J. Parkin regulates programmed necrosis and myocardial ischemia/reperfusion injury by targeting CypD. Antioxid Redox Signal. 2019;31(16):1-52.

17. Yang J, Zhang F, Shi H, Gao Y, Dong Z, Ma L, et al. Neutrophil-derived advanced glycation end products-NE-(carboxymethyl) lysine promotes RIP3-mediated myocardial necroptosis via RAGE and exacerbates myocardial ischemia/reperfusion injury. FASEB J. 2019;33:1-13.

18. Zhang J, Yu P, Hua F, Hu Y, Yu S. Sevoflurane postconditioning reduces myocardial ischemia reperfusion injury induced necroptosis by up-regulation of OGT mediated O-GICNAcylated RIPK3. Aging. 2020;12(24):1-17.

19. Wen Z, Hou W, Wu W, Zhao Y, Song L. 6'-O-galloylpaeoniflorin attenuates cerebral ischemia reperfusion-induced neuroinflammation and oxidative stress via PI3K/Akt/Nrf2 activation. Oxid Med Cell Longev. 2018:2018:1-14.

20. Jiang $L$, Yin $X$, Chen $Y H$, Chen $Y$, Li J. Proteomic analysis reveals ginsenoside $\mathrm{Rb} 1$ attenuates myocardial ischemia/reperfusion injury through inhibiting ROS production from mitochondrial complex I. Theranostics. 2021:11(4):1703-20.

21. Ren J, Fu L, Nile SH, Zhang J, Kai G. Salvia miltiorrhiza in treating cardiovascular diseases: a review on its pharmacological and clinical applications. Front Immunol. 2019;10:1-15.

22. Dai C, Liu Y, Don Z. Tanshinone I alleviates motor and cognitive impairments via suppressing oxidative stress in the neonatal rats after hypoxicischemic brain damage. Mol Brain. 2017:10(1):1-11.

23. Yuan R, Huang L, Du L-J, Feng J-F, Li J. Dihydrotanshinone exhibits an antiinflammatory effect in vitro and in vivo through blocking TLR4 dimerization. Pharmacol Res. 2019:142:102-14.

24. Gao H, Cui Y, Kang N, Liu X, Yue Y. Isoacteoside, a dihydroxyphenylethyl glycoside, exhibits anti-inflammatory effects through blocking toll-like receptor 4 dimerization. Br J Pharmacol. 2017;174(17):2880-96.

25. Luo Y, Li J, Hu Y, Gao F, Pak-Heng Leung G, Geng F, et al. Injectable thermo-responsive nano-hydrogel loading triptolide for the anti-breast cancer enhancement via localized treatment based on "two strikes" effects. Acta Pharm Sin B. 2020;10(11):2227-45.

26. Shi ZW, Ge LS, LiYC. The role of necroptosis in cardiovascular disease. Front Pharmacol. 2018;9:1-9.

27. Yue $L A, Z c A, K e W B, X u e Z B, Y a A, W s a C$, et al. Procyanidin $B 2$ and rutin in Ginkgo biloba extracts protect human retinal pigment epithelial (RPE) cells from oxidative stress by modulating Nrf2 and Erk1/2 signalling. Exp Eye Res. 2021;207:1-13.

28. Zhao W, Feng H, Sun W, Liu K, Lu JJ, Chen X. Tert-butyl hydroperoxide (t-BHP) induced apoptosis and necroptosis in endothelial cells: roles of NOX4 and mitochondrion. Redox Biol. 2017;11:524-34.

29. Han S, Gao H, Chen S, Wang Q, Li X, Du LJ, et al. Procyanidin A1 alleviates inflammatory response induced by LPS through NF-KB, MAPK, and Nrf2/ HO-1 pathways in RAW264.7 cells. Sci Rep. 2019;9(1):1-13.

30. Ali T, Kim T, Rehman SU, Khan MS, Amin FU, Khan M, et al. Natural dietary supplementation of anthocyanins via PI3K/Akt/Nrf2/HO-1 pathways mitigate oxidative stress, neurodegeneration, and memory impairment in a mouse model of Alzheimer's disease. Mol Neurobiol. 2017;55(7):6076-93.

31. Li ST, Dai Q, Zhang SX, Liu YJ, Yu QQ, Tan F, et al. Ulinastatin attenuates LPS-induced inflammation in mouse macrophage RAW264.7 cells by inhibiting the JNK/NF-KB signaling pathway and activating the PI3K/Akt/ Nrf2 pathway. Acta Pharmacol Sin. 2018;39(8):1294-304.

32. He J, Yuan R, Cui X, Cui Y, Gao H. Anemoside B4 protects against Klebsiella pneumoniae- and influenza virus FM1-induced pneumonia via the TLR4/ Myd88 signaling pathway in mice. Chin Med. 2020;15(1):1-13.

33. England BR, Thiele GM, Anderson DR, Mikuls TR. Increased cardiovascular risk in rheumatoid arthritis: mechanisms and implications. BMJ. 2018:361:1-17.

34. Wu YT, Bi YM, Tan ZB, Xie LP, Xu HL, Fan HJ, et al. Tanshinone I inhibits vascular smooth muscle cell proliferation by targeting insulin-like growth factor-1 receptor/phosphatidylinositol-3-kinase signaling pathway. Eur J Pharmacol. 2019:853:93-102.

35. Cui S, Chen S, Wu Q, Chen T, Li S. A network pharmacology approach to investigate the anti-inflammatory mechanism of effective ingredients from Salvia miltiorrhiza. Int Immunopharmacol. 2020;81:1-9.

36. Wang X, Fan J, Ding X, Sun Y, Cui Z, Liu W. Tanshinone I inhibits IL-1 $\beta$ induced apoptosis, inflammation and extracellular matrix degradation in chondrocytes $\mathrm{CHON}-001$ cells and attenuates murine osteoarthritis. Drug Des Dev Ther. 2019:13:3559-68. 
37. Wang S, Jing H, Yang H, Liu Z, Guo H, Chai L, et al. Tanshinone I selectively suppresses pro-inflammatory genes expression in activated microglia and prevents nigrostriatal dopaminergic neurodegeneration in a mouse model of Parkinson's disease. J Ethnopharmacol. 2015;164:247-55.

38. Kim SY, Moon TC, Chang HW, Son KH, Kim HP. Effects of tanshinone isolated from Salvia miltiorrhiza bunge on arachidonic acid metabolism and in vivo inflammatory responses. Phytother Res. 2010;16(7):616-20.

39. Lu LQ, Tian J, Luo XJ, Peng J. Targeting the pathways of regulated necrosis: a potential strategy for alleviation of cardio-cerebrovascular injury. Cell Mol Life Sci CMLS. 2020;78(1):63-78.

40. Bai Y, Lam HC, Lei X. Dissecting programmed cell death with small molecules. Acc Chem Res. 2020;53(5):1034-45.

41. Zhao J, Jitkaew S, Cai Z, Choksi S, Li Q, Luo J, et al. Mixed lineage kinase domain-like is a key receptor interacting protein 3 downstream component of TNF-induced necrosis. Proc Natl Acad Sci. 2012;109(14):5322-7.

42. Gao X, Zhang H, Zhuang W, Yuan G, Dong H. PEDF and PEDF-derived peptide 44 mer protect cardiomyocytes against hypoxia-induced apoptosis and necroptosis via anti-oxidative effect. Sci Rep. 2014;4:1-7.

43. Terluk MR, Ebeling MC, Fisher CR, Kapphahn RJ, Ferrington DA. N-AcetylL-cysteine protects human retinal pigment epithelial cells from oxidative damage: implications for age-related macular degeneration. Oxid Med Cell Longev. 2019;2019(3):1-14.

44. Wang $Z$, Wang $Y$, Ye J, Lu X, Cheng $Y$, Xiang L, et al. bFGF attenuates endoplasmic reticulum stress and mitochondrial injury on myocardial ischaemia/reperfusion viaactivation of PI3K/Akt/ERK1/2 pathway. J Cell Mol Med. 2015;19(3):595-607.

45. Wang QQ, Gao H, Yuan R, Han S, Yang S. Procyanidin A2, a polyphenolic compound, exerts anti-inflammatory and anti-oxidative activity in lipopolysaccharide-stimulated RAW2647 cells. PLoS ONE. 2020;15(8):e0237017.

46. Ibáñez B, Heusch G, Ovize M, Werf FVD. Evolving therapies for myocardial ischemia/reperfusion injury. J Am Coll Cardiol. 2015;65(14):1454-71.

47. Chen $H$, Tang $L$, Tu H, Zhou YJ, Peng J. Arctiin protects rat heart against ischemia/reperfusion injury via a mechanism involving reduction of necroptosis. Eur J Pharmacol. 2020;875:1-12.

48. Tummers B, Green DR. Caspase-8: regulating life and death. Immunol Rev. 2017;277(1):76-89.

49. Machikas GA, Jackson MA, Hope KD. Inhibition of programmed necrosis limits infarct size through altered mitochondrial and immune responses in the aged female rat heart. Am J Physiol Heart Circ Physiol. 2018;315(5):1-13.

50. Nam HH, Nan L, Choo BK. Inhibitory effects of camellia japonica on cell inflammation and acute rat reflux esophagitis. Chin Med. 2021; 16(1): $1-12$
51. Kurian GA, Suryanarayanan S, Raman A, Padikkala J. Antioxidant effects of ethyl acetate extract of desmodium gangeticum root on myocardial ischemia reperfusion injury in rat hearts. Chin Med. 2010;5(1):1-7.

52. Hausenloy DJ, Yellon DM. Myocardial ischemia-reperfusion injury: a neglected therapeutic target. J Clin Investig. 2013;123(1):92-100.

53. XuT, Ding W, Ji X, Ao X, Liu Y, Yu W, et al. Oxidative stress in cell death and cardiovascular diseases. Oxid Med Cell Longev. 2019;2019:1-12.

54. Milaeva ER. The role of radical reactions in organomercurials impact on lipid peroxidation. J Inorg Biochem. 2006;99(5-6):905-15.

55. Li XX, Zheng X, Liu Z, Xu Q, Tang H, Feng J, et al. Cryptotanshinone from Salvia miltiorrhiza Bunge (Danshen) inhibited inflammatory responses via TLR4/MyD88 signaling pathway. Chin Med. 2020;15:1-13.

56. Fan Q, Tao R, Zhang H, Xie H, Lu L, Wang T, et al. Dectin-1 contributes to myocardial ischemia-reperfusion injury by regulating macrophage polarization and neutrophil infiltration. Circulation. 2018;139(5):663-78.

57. Yu P, Li Y, Fu W, Li X, Sui D. Panax quinquefolius L. saponins protect myocardial ischemia reperfusion no-reflow through inhibiting the activation of NLRP3 inflammasome via TLR4/MyD88/NF-KB signaling pathway. Front Pharmacol. 2021;11:1-13.

58. Rui Z, Dan H, Li Z, Shen C, Zhang Y, Li J, et al. Ginkgolide C alleviates myocardial ischemia/reperfusion-induced inflammatory injury via inhibition of CD40-NF-kB pathway. Front Pharmacol. 2018;9:1-15.

59. Ramos IT, Henningsson M, Nezafat M, Lavin B, Lorrio S, Gebhardt P, et al. Simultaneous assessment of cardiac inflammation and extracellular matrix remodeling after myocardial infarction. Circ Cardiovasc Imaging. 2018;11(11):1-13.

60. Gao $S$, Wang $T$, Huang $X K$, Jin $Y$, Wang J. Exploring the protective effect of modified Xiaochaihu Decoction against hepatic steatosis and inflammation by network pharmacology and validation in ageing rats. Chin Med. 2020;15(1):1-19.

61. Sang W, Zhong Z, Linghu K, Xiong W, Tse AKW, Cheang WS, et al. Siegesbeckia pubescens Makino inhibits Pam(3)CSK(4)-induced inflammation in RAW 264.7 macrophages through suppressing TLR1/TLR2-mediated NF-KB activation. Chin Med. 2018;13(1):1-10.

62. Kato T, Noma K, Ohara T, Kashima H, Fujiwara T. Cancer-associated fibroblasts affect intratumoral CD8 + and FoxP3 + T cells via interleukin 6 in the tumor microenvironment. Clin Cancer Res. 2018;24(19):4820-33.

\section{Publisher's Note}

Springer Nature remains neutral with regard to jurisdictional claims in published maps and institutional affiliations. 